\title{
Will subsidies drive electric vehicle adoption? Measuring consumer preferences in the U.S. and China
}

\author{
John Paul Helveston ${ }^{\mathrm{a}, 1}$, Yimin Liu ${ }^{\mathrm{b}, 2}$, Elea McDonnell Feit ${ }^{\mathrm{c}, 3}$, Erica Fuchs ${ }^{\mathrm{a}, 4}$, Erica Klampfl ${ }^{\mathrm{b}, 5}$, \\ Jeremy J. Michalek ${ }^{\mathrm{a}, \mathrm{d}, *}$
}

${ }^{a}$ Department of Engineering and Public Policy, Carnegie Mellon University, 5000 Forbes Ave., Pittsburgh, PA 15213, United States

${ }^{\mathrm{b}}$ Ford Motor Company, Dearborn, MI, United States

' Department of Marketing, Drexel University, 828 Gerri C. LeBow Hall, 3141 Chestnut St., Philadelphia, PA 19104, United States

${ }^{\mathrm{d}}$ Department of Mechanical Engineering, Carnegie Mellon University, 5000 Forbes Ave., Pittsburgh, PA 15213, United States

\section{A R T I C L E I N F O}

\section{Article history:}

Received 2 December 2013

Received in revised form 9 January 2015

Accepted 11 January 2015

\section{Keywords:}

Vehicle electrification

Discrete choice modeling

Conjoint analysis

Federal subsidy policy

China

Willingness-to-pay

\begin{abstract}
A B S T R A C $T$
We model consumer preferences for conventional, hybrid electric, plug-in hybrid electric (PHEV), and battery electric (BEV) vehicle technologies in China and the U.S. using data from choice-based conjoint surveys fielded in 2012-2013 in both countries. We find that with the combined bundle of attributes offered by vehicles available today, gasoline vehicles continue in both countries to be most attractive to consumers, and American respondents have significantly lower relative willingness-to-pay for BEV technology than Chinese respondents. While U.S. and Chinese subsidies are similar, favoring vehicles with larger battery packs, differences in consumer preferences lead to different outcomes. Our results suggest that with or without each country's 2012-2013 subsidies, Chinese consumers are willing to adopt today's BEVs and mid-range PHEVs at similar rates relative to their respective gasoline counterparts, whereas American consumers prefer low-range PHEVs despite subsidies. This implies potential for earlier BEV adoption in China, given adequate supply. While there are clear national security benefits for adoption of BEVs in China, the local and global social impact is unclear: With higher electricity generation emissions in China, a transition to BEVs may reduce oil consumption at the expense of increased air pollution and/or greenhouse gas emissions. On the other hand, demand from China could increase global incentives for electric vehicle technology development with the potential to reduce emissions in countries where electricity generation is associated with lower emissions.
\end{abstract}

(c) 2015 Elsevier Ltd. All rights reserved.

\footnotetext{
* Corresponding author at: Department of Engineering and Public Policy and Department of Mechanical Engineering, Carnegie Mellon University, Scaife Hall 324, 5000 Forbes Ave., Pittsburgh, PA 15213, United States. Tel.: +1 (412) 2683765.

E-mail addresses: john@cmu.edu (J.P. Helveston), yliu59@ford.com (Y. Liu), emf75@drexel.edu (E.McDonnell Feit), erhf@andrew.cmu.edu (E. Fuchs), eklampfl@ford.com (E. Klampfl), jmichalek@cmu.edu (J.J. Michalek).

${ }^{1}$ Tel.: +1 (757) 5033500 .

2 Tel.: +1 (626) 2510017.

3 Tel.: +1 (215) 5714054 .

4 Tel.: +1 (412) 2681877.

5 Tel.: +1 (313) 2484932 .
} 


\section{Introduction}

\subsection{The confluence of two trends in the global automotive industry}

Motor vehicles consume one third of all oil used globally, two thirds of oil used in the U.S., and half of oil used in China (Davis et al., 2013; Ma et al., 2012). Together, China and the U.S. consume approximately one third of all oil consumed globally each year (U.S. EIA, 2014). In the U.S., passenger cars are responsible for $20 \%$ of annual greenhouse gas (GHG) emissions as well as $40 \%$ of volatile organic compound (VOC) emissions, $77 \%$ of carbon monoxide (CO) emissions, and $49 \%$ of nitrogen dioxide $\left(\mathrm{NO}_{\mathrm{x}}\right)$ emissions (U.S. EIA, 2011). In China the emissions levels are comparable, with even higher portions of CO and $\mathrm{NO}_{\mathrm{x}}$ emissions attributable to passenger vehicles (Lang et al., 2013). In addition, increasing China and U.S. dependency on foreign oil poses significant security implications, since both countries currently import nearly half of their annual oil consumption (see Fig. 1) (U.S. EIA, 2014).

At the same time that concerns about oil use are growing, the composition of the vehicle market is rapidly evolving. While vehicle ownership rates within developed countries are nearly static, transitional economies are rapidly adopting personal transportation. Of all the emerging markets, China has the largest growth rate in the world. Chinese passenger car ownership has had an average annual growth rate of $29 \%$ over the past two and a half decades (see Fig. 2). China is now the world's largest passenger vehicle market, a title held since 2009 after surpassing the U.S. (Liu et al., 2010; CATARC, 2009). This growth path should not be expected to stop soon. Currently, with $20 \%$ of the world's population, China has 60 vehicles per thousand people, compared to 800 vehicles per thousand people in the U.S. (National Bureau of Statistics of China, 2013; U.S. FHWA, 2013).

\subsection{Implications of vehicle electrification for emissions and oil consumption}

In the context of this study, we define vehicle electrification to include both gasoline HEVs and plug-in PHEVs/BEVs. HEVs take net propulsion energy from gasoline but utilize a small battery pack and electric motor to improve fuel efficiency, mostly through regenerative braking, engine downsizing, engine shutoff at idle, and power management. PHEVs are similar to HEVs, except they typically have a larger battery pack that can be charged by plugging into an electrical outlet. PHEVs can be driven for short distances (usually less than 40 miles) using only or mostly electricity before switching to gasoline for an extended range. BEVs run purely on electricity and do not use gasoline. They have large battery packs and large electric motors and must be plugged into an electrical outlet to charge. Table 1 summarizes these three technologies.

Each vehicle electrification technology offers some potential to reduce air emissions and oil consumption compared to conventional vehicles. While HEVs continue to rely on gasoline, they reduce both air emissions and oil consumption. PHEVs use grid electricity to displace additional gasoline, and BEVs displace gasoline entirely, but air emissions implications for plug-in vehicles depend on battery manufacturing and the mix of sources used to generate electricity (Samaras and Meisterling, 2008; Elgowainy et al., 2010; Michalek et al., 2011). Seventy-five percent of China's electricity and 42\% of U.S. electricity is generated by burning coal, with its greenhouse gas and air quality implications (Liu et al., 2010; Lang et al., 2013; Ji et al., 2011; U.S. EIA, 2011). While plug-in vehicles are less effective at reducing GHGs in China due to higher life cycle electricity emissions intensity, they are on average still expected to reduce GHGs relative to CVs by as much as $17 \%$ (depending on adoption rates) with even more substantial reductions in the south, central, and north-west regions (Zhou et al., 2013). Fig. 3 summarizes this effect and shows the average emissions intensity of electricity generation in the U.S. and in China. Importantly, emissions vary by region and time of day within each country, and marginal emissions intensities relevant for added electric vehicle charging load are typically higher than average emissions intensities shown in Fig. 3 because dispatchable plants tend to be fossil fuel plants (Siler-Evans et al., 2012; Graff Zivin et al., 2014). Plug-in vehicles

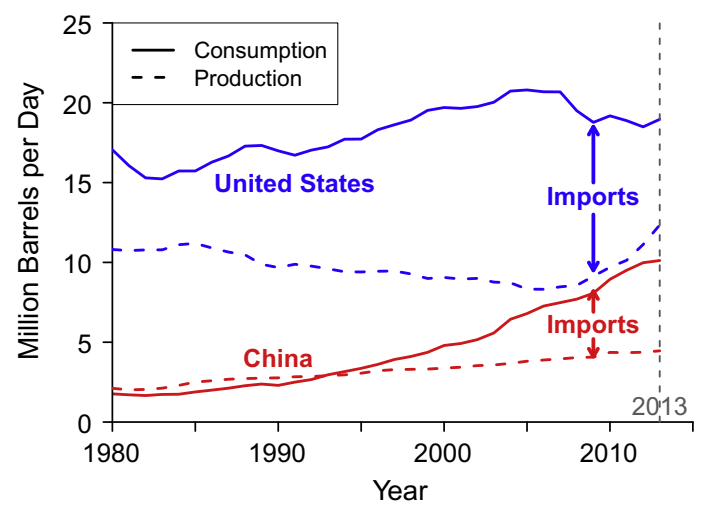

Fig. 1. Growth in U.S. and China dependency on foreign oil (U.S. EIA, 2014). 


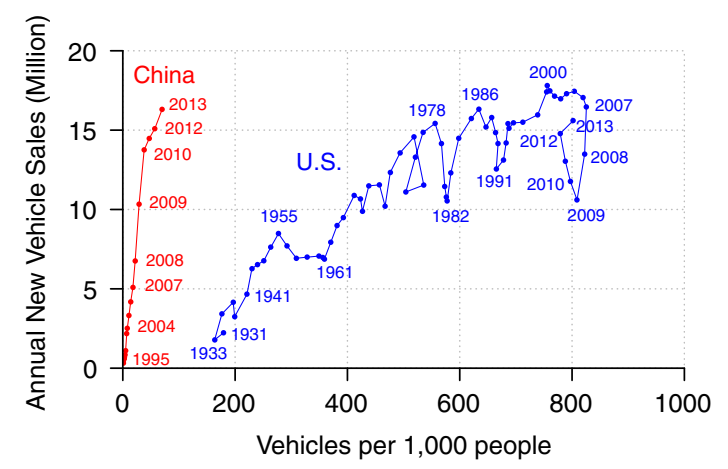

Fig. 2. Growth in Chinese passenger vehicle sales and ownership (National Bureau of Statistics of China, 2013; U.S. FHWA, 2013).

Table 1

Summary of electrified vehicle powertrains.

\begin{tabular}{|c|c|c|c|}
\hline Vehicle type & $\begin{array}{l}\text { Battery } \\
\text { size }\end{array}$ & $\begin{array}{l}\text { Typical Electric } \\
\text { Range (miles) }\end{array}$ & Description \\
\hline $\begin{array}{l}\text { Hybrid electric } \\
\text { (HEV) }\end{array}$ & Small & 0 & More efficient gasoline powertrain through use of small electric motor and battery pack \\
\hline $\begin{array}{l}\text { Plug-in hybrid } \\
\text { electric (PHEV) }\end{array}$ & $\begin{array}{l}\text { Small- } \\
\text { medium }\end{array}$ & $5-40$ & $\begin{array}{l}\text { Larger battery pack than HEV. Can be plugged-into charge, uses electricity to propel for } \\
\text { short distances and gas for longer distances }\end{array}$ \\
\hline $\begin{array}{l}\text { Battery electric } \\
\quad(\mathrm{BEV})\end{array}$ & Large & $75-250$ & Electric motor and large battery pack. Must be plugged-into an electrical outlet to charge \\
\hline
\end{tabular}

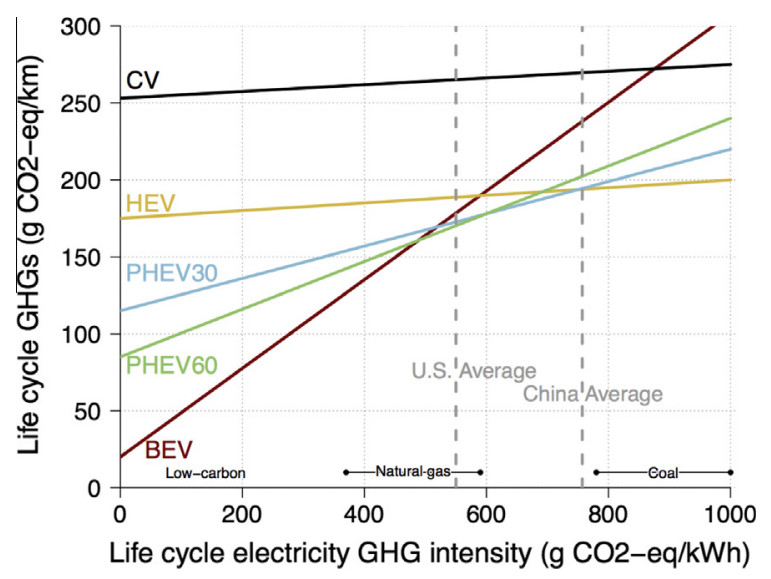

Fig. 3. Life cycle GHG emissions from vehicles shown as a function of the life cycle GHG intensity of the electricity generation (adapted from Samaras and Meisterling (2008)).

also replace tailpipe emissions with power plant emissions, potentially reducing exposure to harmful air pollution in urban centers depending on plant location and wind patterns, though in China this may actually result in increases in primary $\mathrm{PM}_{2.5}$ environmental health impacts per passenger-km (Ji et al., 2011).

Further, the emissions benefits of electrified vehicles depend on the fuel to which it is being compared. Because of China's limited supply of petroleum, it is promoting not only electrified vehicles but also coal-to-liquids - a GHG-intensive way to produce gasoline (Jaramillo et al., 2009). Fuel quality is also different in China. While China has already implemented a policy to phase out lead fuel, the sulfur levels of most Chinese petroleum products remain high. A high sulfur level in gasoline limits the ability of catalytic converters in automobiles to lower $\mathrm{CO}, \mathrm{HC}$, and $\mathrm{NO}_{\mathrm{x}}$ emissions. Depending on shifts in government regulation, these national differences could have a significant impact on the relative competitiveness of alternative powertrains and their implications.

\subsection{Government incentives and consumer preferences}

Both the U.S. and Chinese governments offer numerous incentives for plug-in vehicles, such as tax credits and high occupancy vehicle (HOV) lane exemptions. The U.S. Department of Energy offers details of federal and state incentives in 
the United States (U.S. DOE, 2013b, 2013c), and Zheng et al. (2012) and provide a detailed review of the relevant policies for EV development in China. We focus on federal subsidies for PHEVs and BEVs for two reasons: (1) the U.S. and Chinese subsidies have similar structures and (2) these are national subsidies, and state or provincial level incentives are too geographically specific for our scope. The federal subsidies in each country increase proportionally with the vehicle's battery capacity from a baseline up to a maximum of $\$ 7500$ in the U.S. and $\$ 9400$ in China (U.S. Congress, 2009; State Council, 2012). While both subsidies favor larger-battery PHEVs and BEVs, there is some evidence that smaller-battery HEVs and PHEVs do more to reduce the negative impacts from passenger cars per dollar spent (Michalek et al., 2011).

But even with an incentive structure that favors the most technically efficient products, mass adoption of hybrid and electric vehicles will not occur if the incentives are insufficient to induce consumers to buy them. Understanding consumer preferences allows us to identify tensions between consumer preferences, government incentives, and social benefits and begin to answer related policy questions, such as what would need to happen (e.g. changing key vehicle attributes or policy options) to achieve mainstream adoption of hybrid and electric vehicles.

Given the size of China's passenger vehicle market, the future of vehicle technologies globally could be tied to market trends in China. In 2011, one in four passenger vehicles made globally were made in China (OICA, 2013). At the same time, China is becoming an increasingly important market for many global automakers. For example, Buick, Volkswagen, and Honda now sell $77 \%, 21 \%$, and $20 \%$ of their global sales in China, respectively (LMC Automotive, 2011). As the world's leading automakers navigate China's regulatory environment and the preferences of Chinese consumers during strategic planning of vehicle platforms, the trends in China's market have the potential to change the competitiveness of emerging technologies worldwide (Fuchs, 2014).

\subsection{Research questions}

We design and field a controlled conjoint experiment in both China and the U.S., and we construct and estimate discrete choice models to quantify preferences for different vehicle technologies and attributes. We focus our analysis on the following key research questions:

1. How do U.S. and Chinese preferences for electrified vehicle technologies and attributes compare?

2. How would plug-in vehicles compete against their gasoline counterparts in each country without subsidies?

3. How do subsidies influence the competitiveness of plug-in vehicles vs. their gasoline counterparts?

We address question 1 by estimating consumer WTP for incremental changes in vehicle attributes based on conjoint data. We address questions 2 and 3 via market simulations where pairs of selected plug-in vehicles and their gasoline counterparts compete against one another in the U.S. and Chinese markets both with and without subsidies.

\section{Method}

Given the limited history of plug-in vehicle sales in the U.S. and China and the complications of regional regulations, supply limitations, incentives, mandates, and non-representative early-adopter preferences, historical sales data offer limited information about potential mainstream adoption of electrified vehicles. Stated choice methods provide an alternative approach for understanding potential future mainstream adoption. For these reasons, we use choice-based conjoint (CBC) analysis to measure consumer preferences. In CBC analysis, participants in a survey experiment are asked to compare several product profiles (each defined by a set of attributes, such as price, brand, type, etc.) and choose the product they are most likely to buy. Discrete choice models are then used to infer the relative importance of each attribute in determining consumer choice (Train, 2009). Because the experiment is controlled, we avoid many of the pitfalls of using historic sales data, such as multicolinearity, endogeneity, missing attributes, and a lack of information about consumers, the attributes they observed, and the alternatives they considered (Feit et al., 2010; Louviere et al., 2000). However, the key disadvantage of controlled conjoint experiments is the potential difference between a consumer's choice behavior in the hypothetical survey conditions we create vs. choice behavior in the market when real money is being spent in the point-of-purchase context. We attempt to mitigate these sources of error by targeting new car buyers and presenting choice questions in a way that mimics real purchase decisions (choose one among a set of concrete alternatives). For this research, we design and field equivalent controlled survey experiments in China and the U.S. during the summer of 2012 and spring of 2013.

\subsection{Literature on measuring vehicle preferences}

Many previous studies have applied conjoint analysis and/or discrete choice models to examine automobile demand. Lave and Train (1979) were the first to apply a multinomial logit model to survey data of new car buyers to examine how vehicle attributes and consumer covariates influence choice. Boyd and Mellman (1980) extended the multinomial logit model using the hedonic demand model, also known as the "random coefficients logit model," which incorporates variation in consumer tastes and preferences. Others further improved upon these modeling techniques by using mixed logit models, which allow for more flexible substitution patterns (Brownstone and Train, 1999; McFadden and Train, 2000). Berry et al. (1995) 
proposed a method to deal with endogeneity, which enables regression based on market data rather than survey data. Other model classes have also been applied, such as the multiple discrete-continuous extreme value (MDCEV) model used to model vehicle type and use in cases where households may hold multiple vehicle types with different usage patterns (Bhat and Sen, 2006; Shin et al., 2012). ${ }^{6}$ Over time, the literature has expanded beyond examining vehicle attributes to stress the importance of consumer characteristics such as travel attitude, personality, lifestyle, and mobility (Choo and Mokhtarian, 2004) as well as socio-demographic factors and environmental awareness (Ziegler, 2012) as important factors that affect vehicle type choice.

Consumer preference models have been used to study multiple topics in the automotive industry. McCarthy (1996) uses a multinomial logit demand model on data from a 1989 nationwide household survey of new vehicle buyers to examine the market price elasticity of demand for automobiles. Goldberg (1998) uses a discrete choice model of auto demand and a continuous model of vehicle utilization from the Consumer Expenditure Survey (1984-1990) to examine the effects of CAFE standards on automobile sales, prices, and fuel consumption. Train and Winston (2007) employ a mixed logit demand model to study the relation between the consumer choice behavior and market share drops of the U.S. automakers in the past decade.

More recent studies have focused on demand for alternative-fuel vehicles (AFVs). Golob et al. (1997) use conjoint analysis to examine fleet demand of AFVs. Others have examined AFVs by combining stated and revealed preference data using multinomial logit and mixed logit models (Brownstone et al., 2000; Axsen et al., 2009). Other methods have used interactive surveys to investigate consumer awareness of and preferences towards AFVs (Axsen and Kurani, 2008).

The majority of studies examining AFVs have been focused on the United States, with only a few in other countries: Ziegler (2012) in Germany; Dagsvik and Liu (2009) in Shanghai, China; and Axsen et al. (2009) in Canada. Comparing results across such studies, however, is challenging because each has differences in survey designs, research objectives, and timing. Our study enables direct comparison of Chinese and American preferences since the surveys fielded in each country were identical in content and presentation and were fielded during relatively close time periods. Thus, the results for each country are directly placed in a comparative context.

\subsection{Survey design}

In designing the choice experiment we sought to balance three study goals: (1) provide sufficient information about consumer preferences, (2) match as closely as possible the survey-taker's experience to the experience of making product choices in the marketplace, and (3) limit the cognitive burden on the respondent. Guided by results from several preparatory interviews and pilot surveys conducted in the spring of 2012, we designed a field experiment with three main parts: (1) a vehicle image section, (2) a choice experiment section, and (3) questions on demographics, experience, knowledge, and attitudes towards driving and electrified vehicles. To facilitate comparisons, the survey design was created to be as similar as possible across the two countries. In addition, we also recorded information about each respondent's previous vehicle purchases as well as daily and annual vehicle miles traveled (VMT). We describe each part in turn.

\subsubsection{Part 1: Vehicle image selection}

Given the limited number of HEVs, PHEVs, and BEVs currently available in the market, some respondents might assume an associated vehicle aesthetic when considering a powertrain type (e.g. visualizing a Toyota Prius when shown an alternative with an HEV powertrain). To control for potential bias from inferred vehicle aesthetics or size/class, we ask respondents early in the survey to choose a vehicle class and select an image of a vehicle they found visually appealing. Once selected, we hold this image fixed at the top of each choice question, informing respondents that each vehicle is exactly the same except for differences in the attributes shown in the choice question (similar to selecting a vehicle options package). This isolates the effect of the attributes from aesthetic or vehicle class choices.

\subsubsection{Part 2: Choice experiment}

The choice section of the conjoint survey consisted of one "warm-up" choice task and 15 choice tasks used in model estimation, with three options in each choice task. We chose this design as a compromise between collecting sufficient data to estimate heterogeneous models and avoiding excessive cognitive load. ${ }^{7}$ The "warm-up" choice task was always shown first and included a clearly dominant alternative (i.e. all attributes identical across alternatives except one was cheaper and more efficient). This warm-up was used as a screener question to identify respondents who did not understand the task or did not take it seriously. Fig. 4 below is an example of a choice task for the U.S. survey.

Each alternative has six attributes - type, brand, purchase price, fast charging capability, fuel cost, and acceleration - each with several levels. We chose these attributes for the following reasons: type, purchase price, fast charging capability, and fuel cost are all necessary attributes to address our research questions, and brand and acceleration were included as critically

\footnotetext{
${ }^{6}$ Because almost no households in China own more than one vehicle, we do not explore the MDCEV model.

7 The literature is mixed on how many questions respondents can reasonably answer. While Bradley and Daly (1994) find a fatigue effect after too many questions, Hess et al. (2012) find the contrary: that such an effect is over-stated in related literature and perhaps non-existent. Given the lack definitive guidance in the literature, we relied on our pilot surveys, which suggested that 15 was an acceptable number of questions while 20 garnered respondent complaints about length.
} 


\begin{tabular}{|c|c|c|c|}
\hline \multicolumn{4}{|c|}{$\begin{array}{c}\text { Suppose these } 3 \text { vehicles below were the only vehicles available for purchase, } \\
\text { which would you choose? }\end{array}$} \\
\hline$\underline{\text { Attribute }}^{\star}$ & Option 1 & Option 2 & Option 3 \\
\hline Vehicle Type (0) & $\begin{array}{l}\text { Conventional } \\
300 \text { mile range on } 1 \text { tank }\end{array}$ & $\begin{array}{l}\text { Plug-In Hybrid } \\
300 \text { mile range on } 1 \text { tank } \\
\text { (first } 40 \text { miles electric) }\end{array}$ & 75 mile range on full charge \\
\hline Brand $(\overline{0})$ & German & American & Japanese \\
\hline Purchase Price (0) & $\$ 18,000$ & $\$ 32,000$ & $\$ 24,000$ \\
\hline Fast Charging Capability (0) & - & Not Available & Available \\
\hline $\begin{array}{l}\text { Operating Cost (Equivalent } \\
\text { Gasoline Fuel Efficiency) }\end{array}$ & $\begin{array}{l}19 \text { cents per mile } \\
\text { (20 MPG equivalent) }\end{array}$ & $\begin{array}{l}12 \text { cents per mile } \\
\text { (30 MPG equivalent) }\end{array}$ & $\begin{array}{l}6 \text { cents per mile } \\
\text { (60 MPG equivalent) }\end{array}$ \\
\hline 0 to $60 \mathrm{mph}$ Acceleration & 8.5 seconds (Wedium-Slow) & 8.5 seconds (Medium-Slow) & 7 seconds (Medium-Fast) \\
\hline & 0 & 0 & 0 \\
\hline
\end{tabular}

Fig. 4. Example choice task for the U.S. (see the Supplemental Information for the equivalent example in Chinese). The attribute values (levels) in each choice task were randomly assigned for each question and each respondent.

important attributes influencing choice (informed by pilot surveys). Vehicle range is treated not as a separate attribute but rather as a component of the vehicle type attribute. The experiment design was fully randomized, meaning that the combination of attribute levels shown for any given alternative for any respondent was randomly selected from the set of all possible combinations. ${ }^{8}$ For vehicle type, we included conventional vehicles (CVs) and HEVs as well as PHEVs and BEVs with varying all-electric range (AER). The AERs for the China survey were given in the km equivalent of the U.S. ranges (within 5\% difference due to rounding in the associated unit). "Brand" was represented using country of origin (e.g.: "Volkswagen" would be "German," and "Ford" would be "American") to maintain a statistically manageable number of alternatives. The "Fast Charging Capability" attribute was a binary attribute indicating whether or not a plug-in vehicle had the ability to charge in under 15 min (the attribute was hidden for CV and HEV powertrains). Operating cost was presented as cost per mile driven due to the mixed fuel types of the different vehicles. The cost-equivalent fuel economy for a conventional gasoline vehicle was provided in parenthesis for reference, since it is a more familiar metric for respondents. The cost-equivalent fuel economy was computed using average gasoline prices in each country (\$3.60/gal in the U.S. and 7.08 RMB/L (\$4.40/gal) in China) and was presented in the most commonly used form for each country (miles/gallon in the U.S. and L/100 km in China). Finally, acceleration performance was provided as the time to accelerate from 0 to 60 miles per hour in the U.S. (0-100 km per hour in China).

For each attribute we included levels that were appropriate for the country. The levels were the same across all surveys for vehicle type, brand, and fast charging capability but were different between each country for purchase price, operating cost, and acceleration time. We chose the levels for these attributes based on the respective sales distributions of vehicles in the 2011 market of each country (approximately the 5th, 25th, 50th, 75th, and 95th percentile values in each case). Table 2 below summarizes the attributes and levels used in each country for the experiment. While we fielded both car and SUV surveys, based on each respondent's indicated preference, we discuss only results of the car surveys here because (1) we received fewer SUV responses, particularly in China, and (2) electric vehicles are being implemented first in cars.

\subsubsection{Part 3: Questions on demographics, experience, knowledge, and attitudes}

The last section of the survey contained demographic questions as well as questions related to personal experience, attitudes, and knowledge about driving and electrified vehicles. We use a 5-point Likert scale to rate preferences for attributes not included in the choice section including storage space, reliability, safety, towing capacity, and outward appearance. We used the same scale to ask about environmental attitudes. We also asked about access to parking, access to vehicle charging, income, sex, age, household size, zip code, education level, number of children, and marital status. The full survey text is presented in the Supplemental Information.

\footnotetext{
${ }^{8}$ While other experimental designs may have yielded more main-effects information, we chose a randomized design that is nearly orthogonal, which allows us to explore interaction effects between attributes and avoids confounding main effects with interaction effects (Sematech, 2006). The questions were randomized for each respondent, which has been shown to increase efficiency for mixed logit models (Sandor and Wedel, 2005) and may compensate for any loss in efficiency relative to a fixed main-effects design.
} 
Table 2

Attributes and levels used in U.S. \& China choice experiments.

\begin{tabular}{|c|c|c|}
\hline \multirow[t]{2}{*}{ Attributes } & \multicolumn{2}{|l|}{ Levels } \\
\hline & U.S. & China \\
\hline Purchase price & $15 / 18 / 24 / 32 / 50(\$ U S D, 1000 s)$ & 60/90/130/170/250 (¥CNY, 1000s) \\
\hline Operating cost & 6/9/12/19 (đ/mi.) & $34 / 42 / 49 / 61($ 分 $/ \mathrm{km})$ \\
\hline Acceleration time & $5.5 / 7 / 8.5 / 10(0-60 \mathrm{mi} / \mathrm{h}, \mathrm{sec})$ & $9 / 11 / 13 / 15(0-100 \mathrm{~km} / \mathrm{h}, \mathrm{sec})$ \\
\hline Vehicle type with AER & $\begin{array}{l}\mathrm{CV} / \mathrm{HEV} / \mathrm{PHEV}_{10} / \mathrm{PHEV}_{20} / \mathrm{PHEV}_{40} / \mathrm{BEV}_{75} / \mathrm{BEV}_{100} / \mathrm{BEV}_{150} \\
(\mathrm{AER} \text { in } \mathrm{mi})\end{array}$ & $\begin{array}{l}\mathrm{CV} / \mathrm{HEV} / \mathrm{PHEV}_{15} / \mathrm{PHEV}_{30} / \mathrm{PHEV}_{60} / \mathrm{BEV}_{120} / \mathrm{BEV}_{160} / \mathrm{BEV}_{240} \\
(\mathrm{AER} \text { in } \mathrm{km})\end{array}$ \\
\hline Brand & \multirow{2}{*}{\multicolumn{2}{|c|}{$\begin{array}{l}\text { German/American/Japanese/Chinese/S. Korean } \\
\text { Available/not available (applicable for PEVs only) }\end{array}$}} \\
\hline Fast charging capability & & \\
\hline
\end{tabular}

\subsection{Data collection}

The goal of our sampling strategy was to approximate the population of new car buyers in each country rather than a representative sample of citizens. In China, the population of new car buyers is concentrated in large urban centers, so we conducted surveys in person in July and August 2012 using laptop computers in four major cities: Beijing, Shanghai, Shenzhen, and Chengdu. We chose these cities for their large passenger vehicle market size, which together account for $35 \%$ of 2010 national sales in China, as well as geographic diversity (Maritz, 2010). In each city, we visited large passenger car markets and surveyed respondents walking through the market, screening first for people who reported being in the market for a new vehicle. In the US, the new car buying market is more diverse and not concentrated in cities, so we took a two-pronged sampling approach. First, we sampled users from Amazon Mechanical Turk (AMT) in September 2012 with the goal of achieving a geographically diverse sample as well as a mix of urban, suburban, and rural new car buyers. We supplemented this sample with an in-person sample in February 2013 at the Pittsburgh Auto Show. Unlike some larger auto shows, the Pittsburgh auto show features primarily mainstream vehicles rather than high-end or concept vehicles, and the audience attracted is composed primarily of ordinary new car buyers rather than auto hobbyists or enthusiasts. We collected the auto show sample primarily to have a U.S. on-the-ground comparison sample to the China sample. We also found that we over-sampled younger, less-wealthy respondents online, so the auto show sample was able to help capture additional older and wealthier U.S. respondents.

In each country, a percentage of the respondents who completed the survey were eliminated from our analysis due to issues with their responses including: (1) completing the survey in under $6 \mathrm{~min}$, the approximate minimum time for completing the survey without randomly answering the choice questions, ${ }^{9}$ or (2) failing to choose the dominant choice in the example question which was fixed for each respondent, indicating that the respondent either misunderstood the task or did not pay close attention to the choice question. All respondents in both countries were screened to have had purchased a car within the last year or have intentions of purchasing a car within the next two years. In both countries respondents filled out computer-based surveys that were equivalent in content and in presentation except for language (English in the U.S., Mandarin Chinese in China) and the values of the attribute levels. The translation of the original English survey into Mandarin was performed by one translator and was subsequently back-translated into English by another translator to assess the translation and ensure equivalent language and descriptions in both surveys. Disputes in translation were resolved by discussion with both translators and within the author team.

In the U.S. we collected 312 respondents online and 103 at the Pittsburgh auto show for a total of 415 . We discarded 29 online and 2 at the auto show (7.5\% of total) based on screening criteria for a total sample size of 384. In China we collected 667 respondents across the four cities and discarded 95 (14\%) based on screening criteria for a total of 572 qualified respondents. Of these, we then discarded all remaining data collected in Beijing (124 respondents) since those data appear to include many random responses. The problems with the Beijing data may have been driven by a number of influences. First, Beijing was the only city for which the surveys were fielded outside in the sun on hot summer days, making it uncomfortable and difficult to take the survey. Second, Beijing was the only city for which the authors were unable to be present to ensure the survey was correctly set up and administered. If we include the Beijing data, we find that all effects in China remain comparable, but just larger in magnitude. With the Beijing data removed, our China sample was 448. About two-thirds of the respondents in all four Chinese cities were first-time vehicle buyers, vs. only approximately $4 \%$ in the U.S. (see Table 3 ).

We compared the age and income distributions of our U.S. and China samples to those of a much larger, representative new car buyer survey obtained from Ford Motor Company and found that we oversampled younger, less wealthy individuals in both countries, with particularly strong oversampling of this population in the U.S. To account for these differences, we weighted the respondents using least squares optimization to match the age and income cumulative distribution functions from our survey to those from the larger survey as closely as possible subject to lower and upper bounds on the weights to avoid placing too much weight on any one respondent. Details of the procedure and a comparison of the resulting distributions are provided in the Supplemental Information.

\footnotetext{
${ }^{9}$ Pilot studies informed expected survey completion times.
} 
Table 3

Summary of sample demographic information in our survey, our weighted results, and the reference survey. Standard deviation is shown in parentheses.

\begin{tabular}{|c|c|c|c|c|c|c|}
\hline & \multicolumn{3}{|l|}{ U.S. } & \multicolumn{3}{|l|}{ China } \\
\hline & Our sample & Weighted sample & Reference sample & Our sample & Weighted sample & Reference sample \\
\hline Household income & $57.3(29.3)$ & $74.3(28.7)$ & $74.8(27.3)$ & $24.1(15.7)$ & $26.1(18)$ & $26.1(17.6)$ \\
\hline Age & $33.9(12.7)$ & $51(14.8)$ & $53.1(15.4)$ & $33.3(10.6)$ & $34.8(7.8)$ & $35.1(7.8)$ \\
\hline Number of children & $0.6(1.1)$ & $1.4(1.4)$ & $0.4(0.8)$ & $0.6(0.6)$ & $0.7(0.6)$ & $0.7(0.6)$ \\
\hline Number of vehicles & $1.8(0.8)$ & $2(0.7)$ & - & $0.4(0.6)$ & $0.5(0.7)$ & - \\
\hline Daily VMT & $22.9(10.4)$ & $23.3(11.4)$ & - & - & - & - \\
\hline Annual VMT & $11,200(4800)$ & $12,461(4628)$ & $11,386(6377)$ & - & - & 10,609 (5995) \\
\hline Household size & $2.7(1.3)$ & $2.7(1.2)$ & $2.5(1.2)$ & $3.3(1.1)$ & $3.3(1.2)$ & $3.2(1)$ \\
\hline Years education & $7.2(1.9)$ & $7.9(2.3)$ & $7.2(2.3)$ & $5.9(1.9)$ & $6(1.8)$ & $5.9(2)$ \\
\hline Percent female & $35.3 \%$ & $32.6 \%$ & $39.3 \%$ & $39.4 \%$ & $41.1 \%$ & $28.7 \%$ \\
\hline Percent married & $44.6 \%$ & $68.9 \%$ & $73.5 \%$ & $55.1 \%$ & $70.2 \%$ & $85.6 \%$ \\
\hline Percent with no children & $72.1 \%$ & $40.3 \%$ & $75.0 \%$ & $52.2 \%$ & $36.5 \%$ & $36.4 \%$ \\
\hline Percent college graduates & $52.3 \%$ & $71.2 \%$ & $53.7 \%$ & $30.6 \%$ & $33.1 \%$ & $34.4 \%$ \\
\hline Percent first time buyers & $4.4 \%$ & $1.3 \%$ & - & $65.4 \%$ & $59.2 \%$ & - \\
\hline$n$ & 384 & 384 & 161,903 & 448 & 448 & 13,469 \\
\hline
\end{tabular}

\subsection{Model specification}

Using a random utility model, we assume each consumer $i$ on each choice occasion (each conjoint question) $t$ will select among a set of alternative $j \in J_{i t}$ the one that offers the greatest utility $u_{i j t}$ :

$$
u_{i j t}=v_{i j}+\varepsilon_{i j t}, \quad j \in J_{i t}
$$

Here, utility is decomposed into an observable component $v_{i j}$ and an unobservable component $\varepsilon_{i j t}$. The observable component $v_{i j}$ is a function of the observable attributes of the product $\mathbf{x}_{j}$, so that $v_{i j}=f_{i}\left(\mathbf{x}_{j}\right)$. The unobservable component $\varepsilon_{i j t}$, which captures the factors not included in $v_{i j}$, is treated as a random variable. Utility $u_{i j t}$ is therefore a random variable, and the probability that consumer $i$ will select product $j$ on choice occasion $t$ is the probability that $u_{i j t}>u_{i k t} \forall k \in J_{i t} \backslash j$.

The observable component $v_{i j}$ is often presumed to be linear, so that $v_{i j}=\boldsymbol{\beta}_{i}^{\prime} \mathbf{x}_{j}$, where $\boldsymbol{\beta}_{i}$ is a vector of coefficients that define the relative importance of the product attributes $\mathbf{x}_{j}$ in driving choice. The linear assumption on $v_{i j}$ results in what is known as a "preference space" model, where the estimated coefficients for $\boldsymbol{\beta}_{i}$ are measured in units of utility. For this study, we use a "willingness-to-pay (WTP) space" model for which the coefficients are in units of dollars - a more intuitive unit of comparison. This specification takes the form of $v_{i j}=\alpha_{i}\left(p_{j}+\gamma_{i}^{\prime} \mathbf{x}_{j}\right)$, where $\alpha_{i}$ is the estimated coefficient for price, $p_{j}$ is the price attribute, $\mathbf{x}_{j}$ is the vector of all other attributes, and $\gamma_{i}$ is the vector of WTP coefficients, which could equivalently be represented as $\boldsymbol{\beta}_{i} / \alpha_{i}$ (Train and Weeks, 2005). ${ }^{10}$

We employ variants of the logit model (one of the most widely adopted choice models), which assume that the unobservable utility $\varepsilon_{i j t}$ has an independent and identically distributed extreme value distribution, yielding a closed-form expression for choice probabilities given by

$$
P_{i j t}=\frac{e^{v_{i j}}}{\sum_{k \in J_{i t}} e^{v_{i k}}}
$$

In order to relax some limiting assumptions from the basic logit model (e.g. the independence from irrelevant alternatives (IIA) property (Train, 2009)), we also apply a random coefficients mixed logit model (McFadden and Train, 2000) in the WTP space, which allows for heterogeneity of preferences across the population and more general substitution patterns. While the basic logit model effectively assumes $\gamma_{i}=\gamma \forall i$ and captures variation in WTP across individuals only in the error term $\varepsilon_{i j t}$, the mixed logit model instead assumes that the $\gamma_{i}$ coefficients are drawn from a parametric distribution. ${ }^{11}$ Following convention, we assume each element $\gamma_{i j}$ of the vector $\gamma_{i}$ is drawn from an independent normal distribution, where $\gamma_{i j} \sim N\left(\mu_{i}, \sigma_{i}^{2}\right)$. We assume a fixed (non-random) $\alpha_{i}$ coefficient for all mixed logit models. While WTP could also be computed from a preference space mixed logit model post hoc, Train and Weeks (2005) show that such estimates have unreasonably large variance in comparison to those from a WTP space model.

Eq. (3) below shows the explicit model used for this study, with explanations of variable names shown in Table 4. Parameters are estimated through maximum likelihood estimation. It is important to note that because $v_{i j}$ is nonlinear in parameters in the WTP space, multiple local maxima could exist, so we use a randomized multistart algorithm to search for a global solution. The full estimation procedure is described in the Supplemental Information.

\footnotetext{
10 For comparison, we also estimate equivalent models in the preference space. Results are shown in the Supplemental Information.

11 Models that include interactions with consumer covariates can also capture variation of preferences across consumers.
} 
Table 4

Description of model variables.

\begin{tabular}{|c|c|}
\hline Variable & Description \\
\hline$p_{j}$ & Price paid in thousands of US dollars \\
\hline $\begin{array}{l}x_{\dot{1}}^{\mathrm{HEV}} \\
x_{\dot{\mathrm{PHEV} \#}}^{\mathrm{BEV} \#} \\
x_{j}^{\mathrm{BEZ}}\end{array}$ & $\begin{array}{l}\text { Dummy for HEV vehicle type }\{1 \text { : yes, } 0: \text { no }\} \text { (base level is CV) } \\
\text { Dummy for PHEV vehicle type with AER of \# miles }\{1: \text { yes, } 0: \text { no }\} \text { (base level is CV) } \\
\text { Dummy for BEV vehicle type with AER of \# miles }\{1: \text { yes, } 0: \text { no }\} \text { (base level is CV) }\end{array}$ \\
\hline $\begin{array}{l}x_{j}^{\text {FASTCHARGE }} \\
x_{j}^{\text {OPCOST }} \\
x_{j}^{\text {ACCEL }}\end{array}$ & $\begin{array}{l}\text { Dummy for whether a vehicle can be rapidly charged in less than } 15 \min \{1: \text { yes, } 0 \text { : no } \\
\text { Operating cost in US cents per mile } \\
\text { Time required to accelerate from } 0 \text { to } 60 \mathrm{mph} \text { or } 0 \text { to } 100 \mathrm{~km} / \mathrm{h} \text { (seconds) }\end{array}$ \\
\hline $\begin{array}{l}x_{j}^{\text {AMERICAN }} \\
x_{j}^{\text {APANESE }} \\
x_{j}^{\text {CHINESE }} \\
x_{j}^{\text {SKOREAN }}\end{array}$ & $\begin{array}{l}\text { Dummy for brand of American origin }\{1 \text { : yes, } 0 \text { : no }\} \text { (base level is German) } \\
\text { Dummy for brand of Japanese origin }\{1 \text { : yes, } 0: \text { no }\} \text { (base level is German) } \\
\text { Dummy for brand of Chinese origin }\{1: \text { yes, } 0: \text { no }\} \text { (base level is German) } \\
\text { Dummy for brand of S. Korean origin }\{1: \text { yes, } 0: \text { no }\} \text { (base level is German) }\end{array}$ \\
\hline
\end{tabular}

a The electric range is shown in miles, though the Chinese survey was in km (see Table 2). We model everything in U.S. units for comparability.

Price :

Type :

Fast Charging Capability :

Performance :

Brand :

Error :

$$
\begin{aligned}
& v_{j}=\alpha_{j} p_{j}+ \\
& \alpha_{j}\left[\gamma_{1} x_{j}^{\text {HEV }}+\gamma_{2} x_{j}^{\text {PHEV10 }}+\gamma_{3} x_{j}^{\text {PHEV20 }}+\gamma_{4} x_{j}^{\text {PHEV40 }}+\right. \\
& \gamma_{5} x_{j}^{\text {BEV75 }}+\gamma_{6} x_{j}^{\text {BEV100 }}+\gamma_{7} x_{j}^{\text {BEV150 }}+ \\
& \gamma_{8}\left(x_{j}^{\text {PHEV10 }}+x_{j}^{\text {PHEV20 }}+x_{j}^{\text {PHEV40 }}\right) x_{j}^{\text {FASTCHARGE }} \\
& \gamma_{9}\left(x_{j}^{\text {BEV75 }}+x_{j}^{\text {BEV100 }}+x_{j}^{\text {BEV150 }}\right) x_{j}^{\text {FSTCHARGE }}+ \\
& \gamma_{10} x_{j}^{\text {OPCOST }}+\gamma_{11} x_{j}^{\text {ACCEL }}+ \\
& \left.\gamma_{12} x_{j}^{\text {AMERICAN }}+\gamma_{13} x_{j}^{\text {APANESE }}+\gamma_{14} x_{j}^{\text {CHINESE }}+\gamma_{15} x_{j}^{\text {S-KOREAN }}\right]+ \\
& \varepsilon_{n j}
\end{aligned}
$$

\section{Results}

Using the model from Eq. (3), we investigate model fit between multinomial logit (MNL) and mixed logit (MXL) models, interpret the model coefficients, and examine the influence of consumer demographic, experience, and attitude information on preferences. We estimate each model for China and the U.S. separately, and because the estimates are in the WTP space they can be directly compared without worry over difference in error scale. Each model is estimated using the data from all respondents from each respective country excluding the Beijing sample and invalid responses. In model 1, we fit a MNL model with fixed coefficients for all covariates as in Eq. (3). In model 2, we fit a MXL model with a fixed price parameter and all other coefficients modeled as independently normally distributed (so the estimated parameters are the mean and variance of the distribution for each coefficient). In each model we weight the sample to match income and age distributions from the new car buyer reference sample (un-weighted model coefficients are provided in the Supplemental Information). The estimates from models 1 and 2 for the U.S. and China are presented in Table $5 .{ }^{12}$ We present the coefficients as $\mu$ and $\sigma$, referring to the parameters of the assumed distribution on $\gamma_{i}$ (e.g. $\gamma_{\text {in }} \sim N\left(\mu_{n}, \sigma_{n}^{2}\right)$ ). For the MNL models, $\gamma=\mu$ and $\sigma=0$.

Comparing fit across the models, the log-likelihood increases when moving from a fixed coefficient MNL model (model 1) to a MXL model with random coefficients (model 2), indicating a better fit to the data (as is expected since the MXL models have more parameters). The Akaike information criterion (AIC) also decreases, suggesting the MXL models do not over-fit the data compared to the MNL models. Another metric for comparing model fit is the McFadden's $R$-squared $\left(M R^{2}\right)$, which is a measure of how much better the estimated model fits the data compared to the null model with all parameters set to zero (the adjusted $M R^{2}$ adjusts for the number of model parameters). For both countries, the $M R^{2}$ values of the MXL models are better than those of the MNL models, further suggesting that the MXL models better fit the data compared to the MNL models.

Going forward, we focus on predictions based on model 2 because in addition to having the better log-likelihood values and AIC, they also avoid the IIA assumption inherent in the MNL models and capture some level of preference heterogeneity in the samples. While we discuss in depth the results from model 2, the following observations can be made across all models:

1. Both U.S. and Chinese consumers dislike $\mathrm{BEV}_{75}$ and $\mathrm{BEV}_{100}$ options relative to alternatives and prefer lower price, operating cost, and acceleration time as well as fast-charging capabilities for both PHEVs and BEVs. ${ }^{13}$

\footnotetext{
${ }_{12}$ For comparison, we also run the equivalent models 1 and 2 in the preference space. Coefficients are shown in the Supplemental Information.

${ }^{13}$ Preference for fast charging capability for BEVs is not significant in the US.
} 
Table 5

Regression Coefficient for weighted U.S. and China models in the WTP space.

\begin{tabular}{|c|c|c|c|c|c|}
\hline \multirow[t]{2}{*}{ Attribute } & \multirow[t]{2}{*}{ Coef. } & \multicolumn{2}{|c|}{ Model 1: MNL } & \multicolumn{2}{|c|}{ Model 2: MXL } \\
\hline & & U.S. & China & U.S. & China \\
\hline Price & $\mu$ & $0.052(0.002)^{* * *}$ & $0.033(0.002)^{* * * *}$ & $0.066(0.003)^{* * *}$ & $0.039(0.002)^{* * *}$ \\
\hline \multicolumn{6}{|c|}{ Powertrain type (base $=C V$ ) } \\
\hline \multirow[t]{2}{*}{ HEV } & $\mu$ & $-1.176(1.611)$ & $4.882(1.917)$ & $-0.418(1.585)$ & $4.962(1.992)$ \\
\hline & $\sigma$ & - & - & $0.188(4.664)$ & $19.403(7.723)$ \\
\hline \multirow[t]{2}{*}{ PHEV10 } & $\mu$ & $0.027(1.782)$ & $-1.291(2.069)$ & $0.822(1.796)$ & $-1.748(2.098)$ \\
\hline & $\sigma$ & - & - & $2.197(5.428)$ & $6.055(8.872)$ \\
\hline \multirow[t]{2}{*}{ PHEV20 } & $\mu$ & $1.695(1.751)$ & $-1.242(2.031)$ & $3.207(1.734)$ & $-2.245(2.074)$ \\
\hline & $\sigma$ & - & - & $8.664(5.719)$ & $4.041(6.792)$ \\
\hline \multirow[t]{2}{*}{ PHEV40 } & $\mu$ & $2.650(1.774)$ & $0.930(2.023)$ & $3.304(1.741)$ & $0.380(2.039)$ \\
\hline & $\sigma$ & - & - & $7.141(5.466)$ & 9.108 (6.179) \\
\hline \multirow[t]{2}{*}{ BEV75 } & $\mu$ & $-20.137(1.978)^{* * * *}$ & $-6.032(2.088)^{* * *}$ & $-18.453(1.934)^{* * * *}$ & $-7.627(2.365)^{* * *}$ \\
\hline & $\sigma$ & - & - & $4.175(6.232)$ & $29.843(7.417)^{* * * *}$ \\
\hline \multirow[t]{2}{*}{ BEV100 } & $\mu$ & $-19.496(1.984)^{* * *}$ & $-8.151(2.144)^{* * *}$ & $-18.947(1.965)^{* * * *}$ & $-10.377(2.286)^{* * * *}$ \\
\hline & $\sigma$ & - & - & $1.898(5.368)$ & $8.600(7.340)$ \\
\hline \multirow[t]{2}{*}{ BEV150 } & $\mu$ & $-13.691(1.959)^{* * *}$ & $1.305(2.050)$ & $-12.727(1.959)^{* * *}$ & $0.616(2.075)$ \\
\hline & $\sigma$ & - & - & $10.486(6.061)$ & $6.973(6.406)$ \\
\hline \multicolumn{6}{|c|}{ Brand $($ base $=$ German) } \\
\hline \multirow[t]{2}{*}{ American } & $\mu$ & $8.188(1.289)^{* * *}$ & $-10.574(1.560)^{* * * *}$ & $7.432(1.268)^{* * *}$ & $-7.612(1.687)^{* * *}$ \\
\hline & $\sigma$ & - & - & 0.665 (3.439) & $19.299(5.866)^{* * * *}$ \\
\hline \multirow[t]{2}{*}{ Japanese } & $\mu$ & $0.934(1.289)$ & $-18.098(1.689)^{* * *}$ & $-0.577(1.289)$ & $-15.169(1.790)^{* * *}$ \\
\hline & $\sigma$ & - & - & $11.765(3.508)^{* * * *}$ & $23.666(5.941)^{* * * *}$ \\
\hline \multirow[t]{2}{*}{ Chinese } & $\mu$ & $-19.008(1.550)^{* * * *}$ & $-9.674(1.509)^{* * *}$ & $-19.848(1.666)^{* * * *}$ & $-6.049(1.691)^{* * *}$ \\
\hline & $\sigma$ & - & - & $8.078(4.173)$ & $34.541(6.544)^{* * *}$ \\
\hline \multirow[t]{2}{*}{ S. Korean } & $\mu$ & $-9.510(1.398)^{* * *}$ & $-19.361(1.725)^{* * * *}$ & $-10.412(1.378)^{* * * *}$ & $-17.774(2.124)^{* * * *}$ \\
\hline & $\sigma$ & - & - & $12.335(3.850)^{* * * *}$ & $54.771(6.171)^{* * * *}$ \\
\hline \multicolumn{6}{|c|}{ Cost and performance } \\
\hline \multirow[t]{2}{*}{ PHEV fast-charge } & $\mu$ & $3.944(1.330)^{* * *}$ & $7.615(1.565)^{* * *}$ & $3.331(1.335)$ & $7.567(1.653)^{* * * *}$ \\
\hline & $\sigma$ & - & - & $8.882(4.396)$ & $20.119(5.449)^{* * *}$ \\
\hline \multirow[t]{2}{*}{ BEV fast-charge } & $\mu$ & $3.343(1.478)$ & $6.662(1.599)^{* * *}$ & $0.030(1.821)$ & $6.428(1.668)^{* * *}$ \\
\hline & $\sigma$ & - & - & $26.237(3.871)^{* * * *}$ & $11.567(5.360)$ \\
\hline \multirow[t]{2}{*}{ Operating cost } & $\mu$ & $-1.598(0.106)^{* * *}$ & $-3.214(0.242)^{* * * *}$ & $-1.626(0.104)^{* * * *}$ & $-3.467(0.267)^{* * *}$ \\
\hline & $\sigma$ & - & - & $0.076(0.247)$ & $3.275(0.968)^{* * *}$ \\
\hline \multirow{2}{*}{ Acceleration time } & $\mu$ & $-1.172(0.255)^{* * *}$ & $-4.651(0.299)^{* * * *}$ & $-1.269(0.293)^{* * *}$ & $-4.878(0.319)^{* * *}$ \\
\hline & $\sigma$ & - & - & $5.766(0.880)^{* * * *}$ & $3.359(0.949)^{* * *}$ \\
\hline \multicolumn{2}{|l|}{ LL: } & -3425.6 & -6788.8 & -3373.1 & -6720.9 \\
\hline \multicolumn{2}{|l|}{ Null model LL: } & -4360.5 & -7487.3 & -4360.6 & -7487.3 \\
\hline \multicolumn{2}{|l|}{ AIC: } & 6883.3 & 13609.6 & 6808.3 & 13503.8 \\
\hline McFadden $R^{2}$ : & & 0.21 & 0.09 & 0.23 & 0.10 \\
\hline Adj. McFadden $R^{2}$ : & & 0.21 & 0.09 & 0.22 & 0.10 \\
\hline Num. of Obs: & & 5760 & 6720 & 5760 & 6720 \\
\hline
\end{tabular}

Standard errors of estimates are presented in parenthesis. Coefficient units are USD $\$ 1000 .{ }^{*} \leqslant 0.05 .{ }^{* *} \leqslant 0.01 .{ }^{* * *} \leqslant 0.001$.

2. Compared to Chinese consumers, U.S. consumers have substantially more disutility for BEV powertrains and are less sensitive to acceleration, operating cost, and fast-charging capabilities for both PHEVs and BEVs.

3. Brand is an important factor for both American and Chinese consumers. Americans have stronger preferences for American, German, and Japanese brands and against Chinese and S. Korean brands, while Chinese consumers have stronger preferences for German brands and against Japanese and South Korean brands.

In addition to models 1 and 2, we also estimate several MNL models (models 3-8) where we interact vehicle attributes (vehicle type, price, and operating cost) with respondent characteristics to examine differences in preferences for different groups of individuals. We run these models in the preference space with the linear observable utility function $v_{i j}=\boldsymbol{\beta}_{i}^{\prime} \mathbf{x}_{j}$ because it is easier to separate out groups by their characteristics in this framework. Model 3 is the base case with no respondent interactions. Models $4-6$ interact the demographic variables income, age, and all other demographic variables, respectively; we separate out income and age from all others to avoid multicolinearity in the models. Model 7 interacts respondent covariates that deal with their past driving experience, and model 8 interacts attitude covariates about environmental friendliness and social status. All model estimates for the U.S. and China are shown in the Supplemental Information.

Broadly, we find that U.S. respondents are less sensitive to price and operating cost if they are older, have higher incomes, have higher education, own more vehicles, and have children. Higher income respondents are also more opposed to any 
electrified vehicle technology (HEV, PHEV, or BEV, regardless of range) compared to lower income buyers. The effect on electrified technologies is so strong that after accounting for income differences the lower income group has a positive effect for HEV and PHEV technologies relative to CVs, ceteris paribus. ${ }^{14}$ Because electrified vehicles typically have higher prices relative to other available conventional gasoline vehicles, these results suggest that the barriers to their adoption in the U.S. may be compounded by demographics. Those who can more easily afford an electrified vehicle are more opposed to them, and those who prefer them have lower incomes and may not be able to afford them.

In contrast to U.S. respondents, Chinese respondents who have higher incomes and higher education are more sensitive to operating cost, and those with larger households are less sensitive to price. While perhaps counterintuitive, it is important to note that operating cost and price are different types of costs. Some car buyers be more sensitive to operating cost to save money but less to price because expensive cars are an important status symbol in Chinese culture. We also find no statistically significant income or age effects with vehicle technology. These results suggest that the higher income buyers who may be more able to afford electrified vehicles may also more highly value their operating cost savings, potentially further increasing their attractiveness. Finally, Chinese respondents with multiple vehicles and those who have access to home charging have statistically significantly positive effects for BEV technology, indicating that charging availability could be an important factor in preference towards pure-electric BEVs.

As might be expected, respondents in both countries who ranked appearing environmentally friendly as important have statistically significantly positive effects for all electrified vehicle technologies relative to conventional gasoline vehicles. For these respondents, they may be willing to pay a positive premium for an HEV, PHEV, or BEV in order to appear more environmentally friendly. Attitude towards being environmentally friendly is among the strongest factors correlated with preference towards any electrified vehicle type in both countries. However, U.S. and Chinese respondents differ on how they view electrified vehicles in terms of social status. U.S. respondents who rated their vehicle as being an important status symbol have statistically significantly positive effects for PHEVs and BEVs whereas Chinese respondents show the opposite effect. These results suggest that electrified vehicles may be viewed as a high-status symbol to U.S. car buyers but not so to Chinese car buyers.

\section{Analysis}

We use the estimated coefficients from model 2 to answer the primary research questions posed in the introduction.

\section{Q1: How do U.S. and Chinese preferences for electrified vehicle technologies and attributes compare?}

Since the coefficients from our models are in the WTP space, we can directly interpret the model coefficients as the amount respondents are willing to pay for incremental changes in each vehicle attribute independently of the other attributes. For example, when examining vehicle type we are comparing a difference in WTP for two vehicles that are identical in every way except for powertrain type (e.g. a CV vs. a HEV, with identical fuel economy, styling, operating cost, price, etc.). The only coefficient that cannot be so readily interpreted is the price coefficient, which is not a WTP estimate but rather an estimated constant that converts dollars to units of utility. It can equivalently be thought of as consumer sensitivity to price relative to the error term, with a larger coefficient signifying greater price sensitivity (more consistent choices). Past research has shown that respondent choices on hypothetical conjoint questions for high cost durables can be less sensitive to price relative to other attributes than when choices are made with real money in the marketplace (Feit et al., 2010), so we expect our estimates of willingness-to-pay may potentially be inflated. Fig. 5 below summarizes the mean WTP for each vehicle attribute in our survey. The error bars represent uncertainty in the mean.

U.S. respondent expected average WTP for BEV technology is $\$ 10,000-\$ 20,000$ lower than $C V$, depending on range - larger than what can be gained in fuel cost savings even if vehicle purchase prices were comparable. And fast charging capability does little to mitigate the drop in WTP. In contrast, expected average Chinese consumer WTP for BEV technology ranges from $\sim \$ 0$ to $\$ 10,000$ lower than CVs, depending on range, with fast charging capability increasing expected average WTP by $\$ 6400$. We also find a large and significant WTP heterogeneity for the lower range $\mathrm{BEV}_{75}$ in China (standard deviation of $\$ 19,000$ ), which becomes substantially smaller with increased range (standard deviation of $\$ 7000$ for a $\mathrm{BEV}_{150}$ ). Such large standard deviations could suggest bimodal preferences. Average WTP for other vehicle technologies are not statistically significantly different from CV in either country, although the expected value of WTP for HEVs is higher in China $(\sim 5000)$, and expected WTP for PHEVs is higher in the US $\left(\sim 3200-3300\right.$ for PHEV $_{20}$ and $\mathrm{PHEV}_{40}$ ).

Parameters for operating cost and acceleration time are both significant and robust to model specification, with consistent signs and orders of magnitude across all models. On average, Chinese respondents are willing to pay nearly double the premiums U.S. respondents are willing to pay for a decrease in operating costs ( $\$ 3000$ and $\$ 1600$ per $\$ 0.01 /$ mile-reduced, respectively), and Chinese respondents are willing to pay nearly three times what U.S. respondents are for a decrease in the 0 to $60 \mathrm{mph}$ acceleration time ( $\$ 5000$ and $\$ 1200$ per $1 \mathrm{~s}$ decrease, respectively), likely in part due to vehicles in the

\footnotetext{
${ }^{14}$ Because a majority of the higher income buyers in our sample are from the Pittsburgh Auto Show, this effect may only be local to car buyers near Pittsburgh.
} 

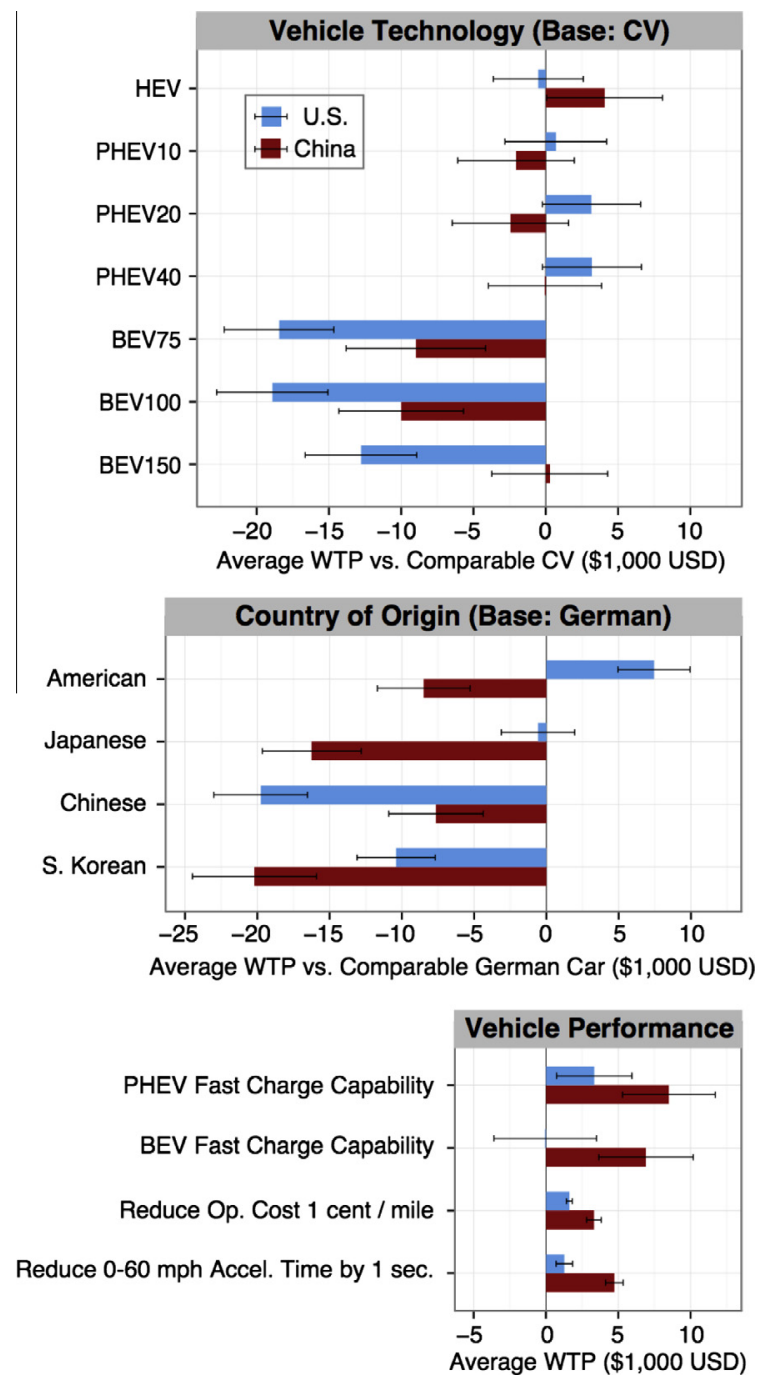

Fig. 5. Mean willingness-to-pay to change each vehicle attribute independently of other attributes in China and the U.S. (Model 2). WTP for vehicle technology indicates preference for the technology alone, independent of any expected influence of that technology on operation cost, performance, or other attributes. Error bars show a $95 \%$ confidence interval for the estimated population mean.

Chinese market having substantially lower acceleration capabilities than those in the U.S. market. These results hold across all models.

Finally, all brand effects are significant with large magnitudes and large, statistically significant differences between the two countries. The brand ranking from most preferred to least preferred, ceteris paribus, for the U.S. is: American, Japanese, German, S. Korean, and Chinese. For China the brand ranking is: German, Chinese, American, Japanese, and S. Korean. We estimate that on average Chinese respondents are willing to pay as much as $\$ 18,000$ and U.S. respondents as much as $\$ 27,000$ to move from equivalent vehicles of the least preferred to the most preferred brands. We find large standard deviations in WTP for brand in both countries, suggesting large heterogeneity in brand preference (as may be expected for passenger vehicles).

Since these results are a comparison of WTP, it is important to note the differences in purchasing power between the two countries. While the average U.S. citizen has a much higher purchasing power than that of the average Chinese citizen, this difference is less extreme between the car-buying populations in each country. Furthermore, the prices shown to survey respondents in each country reflect actual vehicle prices from each respective country. Nonetheless, an equal WTP value in each country may reflect different proportions of an individual consumer's income across the two countries.

Q2: How would plug-in vehicles compete against their gasoline counterparts in each country without subsidies? 


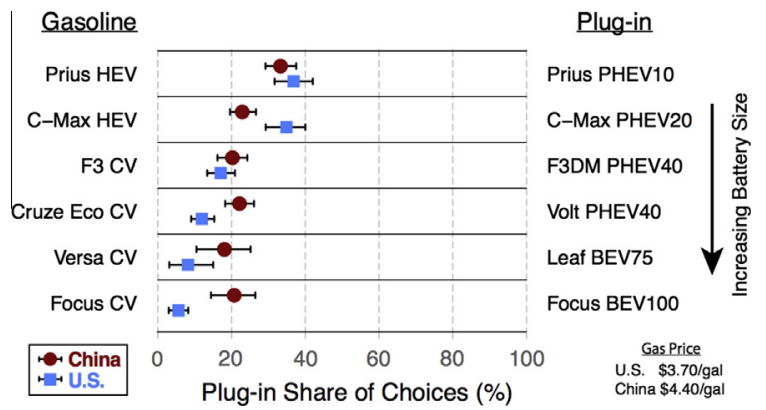

Fig. 6. Predicted share of respondent choices for select plug-in vehicles and their gasoline counterparts in 2012 vehicle attributes. Vehicle attributes used in these simulations are in detailed in the Supplemental Information.

Consumer willingness to adopt plug-in vehicles will depend on the mix of attributes manufacturers are able to offer in a single vehicle (technology type, range, acceleration, operation cost, price, etc.) - not just the vehicle type. To examine the implications of the model coefficients for consumer WTP towards combinations of attributes offered in today's plug-in vehicles, we use model 2 to simulate choice among select plug-in vehicles currently available and their gasoline counterparts. Each simulation is a pairwise comparison of a plug-in vehicle vs. its gasoline counterpart as if they were the only two vehicles available for all car buyers. The conjoint model is not appropriate for making full market forecasts among all vehicles in the marketplace because key attributes that vary across vehicles in the marketplace and drive consumer choice (such as aesthetics, size, etc.) were held constant in the conjoint study. However, the model can be applied to compare vehicles that have identical bodies and differ only in powertrain characteristics captured by the conjoint attributes. Future work may consider joint models using stated and revealed preference data to simulate the entire market (Axsen et al., 2009; Hensher et al., 1999). We run each simulation using 2012 vehicle attributes (as this is the year our data was collected) in different subsidy environments. The attribute values used are listed in the Supplemental Information. Fig. 6 summarizes the simulation results for no subsidy.

We chose vehicles for which the body and general appearance are similar between different vehicle types (such as the Ford Focus $\mathrm{CV}$ and Ford Focus $\mathrm{BEV}_{76}$ (modeled as a $\mathrm{BEV}_{75}$ ), since this mimics how our survey was presented, and since choice models can predict share when all attributes excluded from the model (including aesthetics) are identical across vehicle alternatives or have a negligible effect on choice. It is important to note that these share estimates reflect the expected outcome if every survey respondent selects one vehicle from the two vehicle options available in each case. Since the set of consumers who would consider the two vehicle models in practice is not a random subset of the respondents - and for other reasons such as limited availability of different vehicle models, advertising, incentives, etc. - observed share in the marketplace will differ. Most of these vehicles are not yet available for sale in China and are only available in relatively small numbers in the U.S. In addition, early adopters are driving current plug-in vehicle sales; since our sample is of mainstream car buyers, these simulations allow us to examine larger, mainstream preferences for these technologies.

We make comparisons between six pairs of plug-in and gasoline vehicles: two comparing PHEVs to HEVs, two comparing PHEVs to CVs, and two comparing BEVs to CVs. Without any subsidies, we find that the HEVs are preferred to the PHEVs in both countries. The CVs are also preferred over their PHEV counterparts in both countries to an even larger degree than the HEVs. The only result with a significant difference between the U.S. and China is for the BEV simulations. We find that BEVs compete poorly against their CV counterparts in the U.S. but compete substantially better in China, reaching approximately $20 \%$ share of choices without subsidies, similar to how the PHEVs compete against their CV counterparts.

\section{Q3: How do subsidies influence the competitiveness of plug-in vehicles vs. their gasoline counterparts?}

To examine how federal subsidies might influence plug-in vehicle competitiveness, we run simulations of the same pairs of plug-in and gasoline vehicles under varying subsidy environments, scaling from $\$ 0$ to $\$ 20,000$ per vehicle. Today's national subsidies are summarized in the Supplemental Information. In both the U.S. and in China subsidies vary with battery capacity, providing lower subsidies for small-battery low-range PHEVs and larger subsidies for larger-battery longerrange PHEVs and BEVs. Our sensitivity study covers roughly twice the range of national subsidies observed today. We treat subsidies as though they only affect the price observed by the consumer, although in practice consumer knowledge that a vehicle is being subsidized may influence consumer adoption in other ways for which we lack data, and subsidies in the form of tax breaks may not be realized at full value for all consumers and/or valued on a dollar-per-dollar basis by all consumers. We plot the results of the plug-in vehicle share of choices vs. the subsidy in Fig. 7. The shaded region represents a 95\% confidence interval based on uncertainty in the parameters and was calculated using 10,000 simulated draws from the model described in Eq. (3).

Results suggest that share of BEVs is higher in China than the U.S. and that share of low-range PHEVs is likely higher in the U.S. than in China whenever the two countries have comparable subsidies. Results are inconclusive for the mid-range PHEV cases as shares are similar between the two countries for the BYD case but higher in China for the Chevrolet case (likely a 

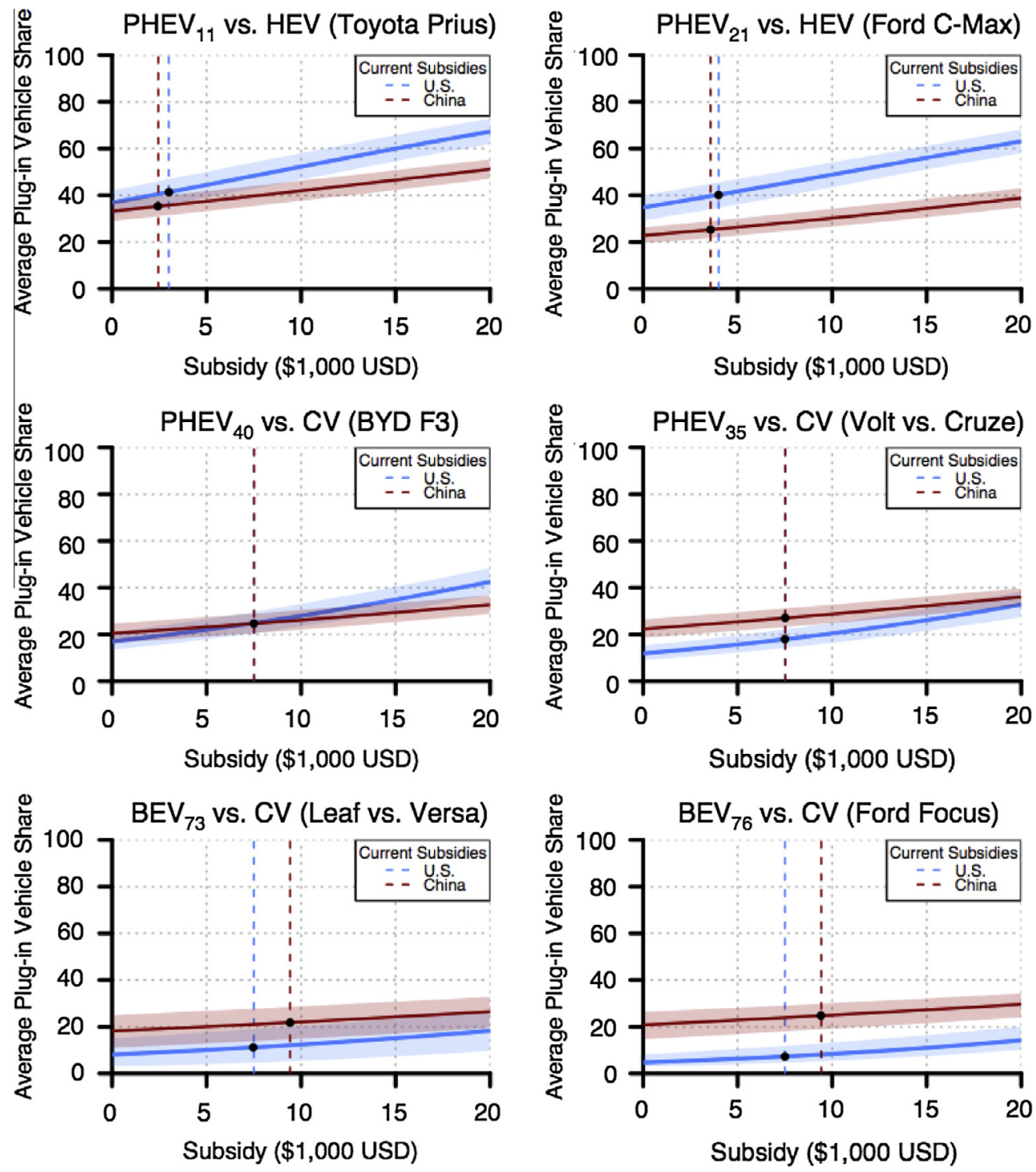

Fig. 7. Simulated share of respondent choices for select plug-in vehicles and their gasoline counterparts, illustrating how share changes with increasing plug-in vehicle subsidies. The vertical lines indicate the current plug-in vehicle subsidy in each country.

result of high price of the Volt relative to the Cruze Eco). To achieve a 50\% share of plug-in vehicles vs. their gasoline counterparts (indicating no net preference for one over the other in the population), the low-range PHEVs would require a U.S. subsidy of about $\$ 9000$ and a Chinese subsidy of $\$ 18,000$ or more. In contrast, the larger battery PHEVs and BEVs would require subsidies exceeding $\$ 20,000$ in both countries to achieve a $50 \%$ share of choices. Under current subsidies, low-range PHEVs could achieve a 41-44\% share in the U.S. and a 32-36\% share in China vs. their respective gasoline counterparts, while larger-battery PHEVs could achieve only a 25-33\% share in the U.S. and a 26-35\% share in China vs. their respective gasoline counterparts. In contrast, the current subsidies for BEVs have substantially different impacts on share between China and the U.S., achieving a $24-25 \%$ share in China while only a $7-12 \%$ share in the U.S. vs. their respective gasoline counterparts.

\section{Limitations}

Both the U.S. and China have a range of policies in addition to federal subsidies that influence adoption of electrified vehicles. For example, in the U.S., state level subsidies for plug-in vehicles as high as $\$ 7500$ per vehicle are added to federal subsidies (U.S. DOE, 2013a); state mandates like California's zero-emission vehicle (ZEV) program force automakers to sell specific technologies, such as electrified vehicles - often at a loss (Collantes and Sperling, 2008); perks like high-occupancy vehicle (HOV) lane access for plug-in vehicles hold high value for some consumers (Dubin et al., 2011); and government fleet 
purchases influence sales. In Beijing, BEV buyers are exempt from going through the city's lottery system to obtain a license plate (only one out of 77 applicants were awarded plates in February, 2013), and local subsidies reach a maximum of $¥ 120,000$ RMB ( $\$ 19,600$ USD) (Xinhua, 2013). For tractability, we do not attempt to assess the effect of local and nonmonetary policies in driving adoption.

Additionally, while our choice-based conjoint study was designed to mitigate bias, consumer decisions in practice may deviate from reported choices in a hypothetical survey environment. As previously noted, it has been observed that respondent choices on hypothetical conjoint questions for high cost durables can be less sensitive to price than choices made with real money in the marketplace (Feit et al., 2010), so we expect estimates of WTP to potentially be somewhat inflated. Further, we use point estimates for fuel economy, gas price, and vehicle price that, in practice, may vary from consumer to consumer (e.g.: city vs. highway driving (Karabasoglu and Michalek, 2013), gas price regional or temporal fluctuations, and vehicle purchase transaction prices via dealer negotiation and financing).

More generally, research has shown that consumer choice often does not follow neoclassical economic assumptions of utility maximization - especially when consumer learning about new technologies is involved. For example, Turrentine and Kurani (2007) provide a useful critique of the utility maximization framework for vehicle fuel economy and offer alternative approaches rooted in anthropological study. In a study of semi-structured interviews of 57 households in California, they found that consumer decisions about fuel economy were more heavily influenced by emotion rather than analysis and that car buyers do not think about fuel economy in terms of payback periods, willingness-to-pay, or other constructs based on the assumption of economic rationality (Turrentine and Kurani, 2007). Furthermore, similar research has shown that sometimes buyers of HEVs make functional compromises in order to gain the symbolic benefits associated with driving a vehicle that is viewed as more environmentally friendly Heffner et al., 2005). Other research has shown that these effects can be further magnified through a "neighbor effect," where "a new technology becomes more desirable as its adoption becomes more widespread in the market" (Axsen et al., 2009). In China, where owning a vehicle is such a strong social status symbol, such effects could be even more influential in driving consumer choice.

It is difficult to separate consumer responses on our survey from the current social and policy environments, which may influence perception of and preferences for electrified vehicles. Further, future vehicles, both conventional and electrified, will have different attributes and prices from today's vehicles. In comparing currently available plug-in vehicles to their current gasoline counterparts, we do not aim to predict current market behavior, especially since current adoption trends are driven by early adopters (Santini and Vyas, 2005), and our samples are of mainstream consumers. Our share simulations are based on the situation where all consumers consider only the plug-in vehicle vs. its gasoline counterpart. In addition, factors other than consumer preferences play a major role in influencing adoption, including policies such as California's ZEV policy (increasing Nissan Leaf sales in California (Collantes and Sperling, 2008)), and supply constraints. China in particular faces large supply constraints, with currently no commercially available BEVs for sale to private owners, and only a small set of HEV models available.

Finally, While our consumer preference results suggest potential for greater BEV adoption in China based on consumer preferences, other factors such as Chinese policies requiring joint venture automotive firms for foreign automakers, intellectual property rights protection in China, firm experience with each technology, and consumer access to off-street parking and authorization for charger installation (Traut et al., 2013) complicate future adoption patterns.

\section{Conclusions and discussion}

Vehicle electrification is one particularly promising option to reduce world wide air emissions and oil consumption, given a sufficiently clean electricity grid. Different vehicle electrification technologies have difference consequences for air emissions (and thus human health) and oil consumption (and thus national security): HEVs reduce gasoline consumption, PHEVs use grid electricity to displace additional gasoline, and BEVs displace gasoline entirely. Air emissions implications for plug-in vehicles (PHEVs and BEVs) depend on battery manufacturing and the mix of sources used to generate electricity.

Vehicle technology adoption in China and the United States is influenced by consumer preferences and public policy. We model consumer preferences for conventional, hybrid electric, plug-in hybrid electric, and battery electric vehicle technologies in China and the U.S. using data from choice-based conjoint surveys fielded in both countries. Results suggest that the expected average U.S. consumer WTP for BEV technology is $\$ 10,000-\$ 20,000$ lower than equivalent conventional technology (depending on range, fast charging availability, and model specification) ceteris paribus (given the same body, brand, performance, and operating cost). In contrast, average Chinese consumer WTP for BEV technology is within $\$ 10,000$ of equivalent conventional vehicles and in some cases (e.g.: with sufficient range and fast charging capability) is larger.

To understand competitiveness of the combined bundle of attributes realized with today's technology, we apply WTP for vehicle type, price, brand, operating cost, and acceleration to attributes of plug-in vehicles available today and their gasoline counterparts. We find that in China, BEVs and mid-range PHEVs both compete comparably with their respective gasoline counterparts, while in the U.S., mid-range PHEVs compete more strongly than BEVs against their respective gasoline counterparts. Low-range PHEVs compete most strongly against their gasoline counterparts in both countries. These patterns hold in both countries with or without the 2012-2013 national subsidies, which favor large-battery PHEVs and BEVs over lowrange PHEVs in both countries. Further, these patterns hold in both countries even if all subsidies were doubled. 
Overall, our results suggest that Chinese respondents are more receptive to BEVs than American respondents regardless of subsidies. The Chinese car market has several key distinctions that might support BEV adoption. First, approximately twothirds of Chinese car buyers are first-time buyers who typically have less experience with both gasoline and plug-in vehicle technology and who may not have established expectations for the ability to take long trips. In addition, many Chinese consumers have experience with electric bicycles, so the culture of plugging in a vehicle and driving short distances is well established. Furthermore, China has a major intercity train system, providing inexpensive and reliable travel between cities. This alternative allows consumers to mode shift to trains during longer trips, an alternative less accessible in the U.S. These preferences, which support the adoption of BEVs, have clear national security benefits for China.

While our consumer preference estimates point to greater potential for mainstream adoption of BEVs in China than the U.S., the electricity grid in China is more emissions-intensive than that of the U.S., and a shift to BEVs might result in increased air pollution and/or GHG emissions, depending on the emissions intensity of the vehicles displaced, marginal grid emissions factors in the regions where EVs are adopted, and driving patterns. In contrast, today's hybrids, which reduce oil consumption and emissions, have higher near term adoption potential in both countries and may therefore offer more total emissions and oil displacement benefits in the near term, given today's electricity grid, technology attributes, and consumer preferences.

Given that China is now the largest consumer and producer of automobiles worldwide, the trends in China's market and the strategies of automakers and government in China have the potential to change the economic incentives for emerging technology development worldwide. Even though EV adoption in China might increase local emissions, global emissions from automobiles could nevertheless plausibly decrease as a result of increased development and adoption of EV technology worldwide.

\section{Acknowledgements}

Special thanks to Jiang Zhijie, Zheng Wei, and Zang Ye at the State Information Center in Beijing for helping organize and conduct the field experiments in China, and the Center for Climate and Energy Decision Making (CEDM) for providing the laptops to field our survey at the Pittsburgh Auto Show. This work was funded in part by a grant from the National Science Foundation \#1064241 and a grant from Ford Motor Company. The opinions expressed are those of the authors and not necessarily those of the sponsors.

\section{Appendix A. Supplementary material}

Supplementary data associated with this article can be found, in the online version, at http://dx.doi.org/10.1016/j.tra. 2015.01.002.

\section{References}

Axsen, J., Kurani, K.S., 2008. The Early U.S. Market for PHEVs: Anticipating Consumer Awareness, Recharge Potential, Design Priorities and Energy Impacts (August).

Axsen, J., Mountain, D.C., Jaccard, M., 2009. Combining stated and revealed choice research to simulate the neighbor effect: the case of hybrid-electric vehicles. Resour. Energy Econ. 31 (3), 221-238. http://dx.doi.org/10.1016/j.reseneeco.2009.02.001.

Berry, S., Levinsohn, J., Pakes, A., 1995. Automobile prices in market Equilibrium Steven. Econometrica 63 (4), 841-890.

Bhat, C.R., Sen, S., 2006. Household vehicle type holdings and usage: an application of the multiple discrete-continuous extreme value (MDCEV) model. Transport. Res. Part B: Methodol. 40 (1), 35-53. http://dx.doi.org/10.1016/j.trb.2005.01.003.

Boyd, J.H., Mellman, R.E., 1980. The effect of fuel economy standards on the U.S. automotive market: an hedonic demand analysis. Transport. Res. Part A: General 14 (5-6), 367-378. http://dx.doi.org/10.1016/0191-2607(80)90055-2.

Bradley, M., Daly, A., 1994. Use of the logit scaling approach to test for rank-order and fatigue effects in stated preference data. Transportation 21 (2), 167184.

Brownstone, D., Train, K.E., 1999. Forecasting new product penetration with flexible substitution patterns. J. Econ. 89

Brownstone, D., Bunch, D.S., Train, K.E., 2000. Joint mixed logit models of stated and revealed preferences for alternative-fuel vehicles. Transport. Res. Part B 34 (5), 315-338. http://dx.doi.org/10.1016/S0191-2615(99)00031-4.

CATARC, 2009. China Automotive Technology and Research Center (CATARC) Automotive Industry Yearbook

Choo, S., Mokhtarian, P.L., 2004. What type of vehicle do people drive? The role of attitude and lifestyle in influencing vehicle type choice. Transport. Res. Part A: Policy Pract. 38 (3), 201-222. http://dx.doi.org/10.1016/j.tra.2003.10.005.

Collantes, G., Sperling, D., 2008. The origin of California's zero emission vehicle mandate. Transport. Res. Part A: Policy Pract. 42 (10), 1302-1313. http:// dx.doi.org/10.1016/j.tra.2008.05.007.

Dagsvik, J.K., Liu, G., 2009. A framework for analyzing rank-ordered data with application to automobile demand. Transport. Res. Part A: Policy Pract. 43 (1), 1-12. http://dx.doi.org/10.1016/j.tra.2008.06.005

Davis, S.C., Diegel, S.W., Boundy, R.G., 2013. Transportation Energy Data Book, 32nd ed. Oak Ridge National Laboratory.

Dubin, J., Barney, R., Csontos, A., Um, J., \& Wu, N. (2011). Realizing the Potential of the Los Angeles Electric Vehicle Market.

Elgowainy, A., Han, J., Poch, L., Wang, M., Vyas, A., Mahalik, M., \& Rousseau, A. (2010). Well-to-Wheels Energy Use and Greenhouse Gas Emissions Analysis of Plug-in Hybrid Electric Vehicles.

Feit, E.M., Beltramo, M.A., Feinberg, F.M., 2010. Reality Check: combining choice experiments with market data to estimate the importance of product attributes. Manage. Sci. 56 (5), 785-800. http://dx.doi.org/10.1287/mnsc.1090.1136.

Fuchs, E.R.H., 2014. Global manufacturing and the future of technology. Science 345 (6196), 519-520.

Goldberg, P.K., 1998. The effects of the corporate average fuel efficiency standards in the US. J. Indust. Econ. 46 (1), 1-33. http://dx.doi.org/10.1111/14676451.00059 (retrieved).

Golob, T.F., Brownstone, D., Bunch, D.S., 1997. Commercial fleet demand for alternative-fuel vehicles in California. Transport. Res. Part A: Policy Pract. 31 (3), 219-233. http://dx.doi.org/10.1016/S0965-8564(96)00017-1. 
Graff Zivin, J.S., Kotchen, M.J., Mansur, E.T., 2014. Spatial and temporal heterogeneity of marginal emissions: implications for electric cars and other electricity-shifting policies. J. Econ. Behav. Org. 107, Part A, 248-268.

Heffner, R.R., Kurani, K.S., Turrentine, T.S., 2005. Effects of Vehicle Image in Gasoline-Hybrid Electric Vehicles. In: 21st Worldwide Battery, Hybrid, and Fuel Cell Electric Vehicle Symposium and Exhibition (EVS-21). Monaco.

Hensher, D.A., Louviere, J., Swait, J., 1999. Combining sources of preference data. J. Econ. 89, 197-221.

Hess, S., Hensher, D.a., Daly, A., 2012. Not bored yet - revisiting respondent fatigue in stated choice experiments. Transport. Res. Part A: Policy Pract. 46 (3), 626-644. http://dx.doi.org/10.1016/j.tra.2011.11.008.

Jaramillo, P., Samaras, C., Wakeley, H., Meisterling, K., 2009. Greenhouse gas implications of using coal for transportation: life cycle assessment of coal-toliquids, plug-in hybrids, and hydrogen pathways. Energy Policy 37 (7), 2689-2695. http://dx.doi.org/10.1016/j.enpol.2009.03.001.

Ji, S., Cherry, C.R., Bechle, M.J., Wu, Y., Marshall, J.D., 2011. Electric vehicles in China: emissions and health impacts. Environ. Sci. Technol. 46 (4), $2018-2024$. http://dx.doi.org/10.1021/es202347q.

Karabasoglu, O., Michalek, J.J., 2013. Influence of driving patterns on life cycle cost and emissions of hybrid and plug-in electric vehicle powertrains. Energy Policy 60, 445-461. http://dx.doi.org/10.1016/j.enpol.2013.03.047.

Lang, J., Cheng, S., Zhou, Y., Zhao, B., Wang, H., Zhang, S., 2013. Energy and environmental implications of hybrid and electric vehicles in China. Energies 6 (5), 2663-2685. http://dx.doi.org/10.3390/en6052663.

Lave, C.A., Train, K.E., 1979. A disaggregate model of auto-type choice. Transport. Res. A 13 (1), 1-9.

Liu, Y., Yang, Y., Klampfl, E., 2010. Energy Challenges the Automobile Industry Faces. In: International Association for Energy Economics Forum, 2nd Quarte, 17-20. <http://www.iaee.org/en/publications/newsletterdl.aspx?id=97?> (retrieved).

LMC Automotive, 2011. China Automotive Monthly Report.

Louviere, J.J., Hensher, D.A., Swait, J.D., 2000. Stated choice methods: analysis and applications. Cambridge University Press.

Ma, L., Fu, F., Li, Z., Liu, P., 2012. Oil development in China: current status and future trends. Energy Policy 45, 43-53. http://dx.doi.org/10.1016/ j.enpol.2012.01.023.

Maritz, 2010. Passenger vehicle sales by city in China, Maritz New Car Buyer Survey.

McCarthy, P.S., 1996. Market price and income elasticities of new vehicle demands. Rev. Econ. Stat. 78 (3), 543. http://dx.doi.org/10.2307/2109802.

McFadden, D., Train, K.E., 2000. Mixed MNL models for discrete response. J. Appl. Econ. 15 (5), 447-470. http://dx.doi.org/10.1002/1099-1255(200009/ 10) $15: 5<447::$ AID-JAE570>3.0.CO;2-1.

Michalek, J.J., Chester, M., Jaramillo, P., Samaras, C., Shiau, C.-S.N., Lave, L.B., 2011. Valuation of plug-in vehicle life-cycle air emissions and oil displacement benefits. Proc. Natl. Acad. Sci. USA 108 (40), 16554-16558. http://dx.doi.org/10.1073/pnas.1104473108.

National Bureau of Statistics of China, 2013. China Statistical Yearbook 2013. China Statistics Press, Beijing, China.

OICA, 2013. World Motor Vehicle Production by Country and Type. <http://www.oica.net/category/production-statistics/> (retrieved)

Samaras, C., Meisterling, K., 2008. Life cycle assessment of greenhouse gas emissions from plug-in hybrid vehicles: implications for policy. Environ. Sci. Technol. 42 (9), 3170-3176. http://dx.doi.org/10.1021/es702178s.

Sandor, Z., Wedel, M., 2005. Heterogeneous conjoint choice designs. J. Mark. Res. 42 (2), 210-218.

Santini, D.J., Vyas, A.D., 2005. Suggestions for a new vehicle choice model simulating advanced vehicles introduction decisions (AVID): structure and coefficients. Transportation.

Sematech, N., 2006. Engineering statistics handbook. NIST SEMATECH. <http://www.itl.nist.gov/div898/handbook/> (retrieved).

Shin, J., Hong, J., Jeong, G., Lee, J., 2012. Impact of electric vehicles on existing car usage: a mixed multiple discrete-continuous extreme value model approach. Transport. Res. Part D: Transport Environ. 17 (2), 138-144. http://dx.doi.org/10.1016/j.trd.2011.10.004.

Siler-Evans, K., Azevedo, I.L., Morgan, M.G., 2012. Marginal emissions factors for the U.S. electricity system. Environ. Sci. Technol. 46 (9), $4742-4748$. http:// dx.doi.org/10.1021/es300145v.

State Council, 2012. Notice about Enacting Energy Efficient and Alternative Energy Vehicles Industry Development Plan (in Chinese). <http://www.gov.cn/ zwgk/2012-??07/09/content_2179032.htm> (retrieved).

Train, K.E., 2009. Discrete Choice Methods with Simulation, second ed. Cambridge University Press.

Train, K.E., Weeks, M., 2005. Discrete choice models in preference space and willingness-to-pay space. Springer, Netherlands, pp. 1-16.

Train, K.E., Winston, C., 2007. Vehicle choice behavior and the declining market share of US automakers. Int. Econ. Rev. 48 (4), $1469-1496$.

Traut, E.J., Cherng, T.C., Hendrickson, C., Michalek, J.J., 2013. US residential charging potential for electric vehicles. Transport. Res. Part D: Transport Environ. 25, 139-145. http://dx.doi.org/10.1016/j.trd.2013.10.001.

Turrentine, T.S., Kurani, K.S., 2007. Car buyers and fuel economy? Energy Policy 35 (2), 1213-1223. http://dx.doi.org/10.1016/j.enpol.2006.03.005.

U.S. Congress, 2009. American Recovery and Reinvestment Act of 2009.

U.S. DOE, 2013a. Comparison of State Incentives for Plug-In Electric Vehicle Purchases. <http://www1.eere.energy.gov/vehiclesandfuels/facts/m/2013 fotw789.html> (retrieved 09.11.13).

U.S. DOE, 2013b. Federal Laws and Incentives for EVs. <http://www.afdc.energy.gov/laws/laws/US/tech/3270> (retrieved 09.04.13).

U.S. DOE, 2013c. Federal Laws and Incentives for HEVs/PHEVs. <http://www.afdc.energy.gov/laws/laws/US/tech/3285> (retrieved 09.04.13).

U.S. EIA, 2011. Annual Energy Review 2011. Washington, D.C.

U.S. EIA, 2014. U.S. Energy Information Administration, International Energy Statistics. <http://www.eia.gov/countries/data.cfm> (retrieved).

U.S. FHWA, 2013. Licensed Drivers, Vehicle Registrations, and Resident Population.

Xinhua, 2013. Beijing Unveils Preferential Policies for Electric Vehicles.

Zheng, J., Mehndiratta, S., Guo, J.Y., Liu, Z., 2012. Strategic policies and demonstration program of electric vehicle in China. Transport Policy 19 (1), 17-25. http://dx.doi.org/10.1016/j.tranpol.2011.07.006.

Zhou, G., Ou, X., Zhang, X., 2013. Development of electric vehicles use in China: a study from the perspective of life-cycle energy consumption and greenhouse gas emissions. Energy Policy 59, 875-884. http://dx.doi.org/10.1016/j.enpol.2013.04.057.

Ziegler, A., 2012. Individual characteristics and stated preferences for alternative energy sources and propulsion technologies in vehicles: a discrete choice analysis for Germany. Transport. Res. Part A: Policy Pract. 46 (8), 1372-1385. http://dx.doi.org/10.1016/j.tra.2012.05.016. 